\title{
Physical and calorific properties of wheat straw briquettes and pellets
}

\author{
Cosmin Spirchez ${ }^{1, *}$, Aurel Lunguleasa ${ }^{1}$, Constantin Ionescu ${ }^{1}$, and Catalin Croitoru $^{2}$ \\ ${ }^{1}$ Transilvania University of Brasov, Wood Processing and Design of Wooden Products Department, \\ 50068 Brasov, Romania \\ ${ }^{2}$ Transivania University of Brasov, Welding and Material Science Department, 50068 Brasov, \\ Romania
}

\begin{abstract}
Wheat straw briquettes are high performance combustible products obtained by densification from the wheat straw biomass without the use of additional adhesives or additives. The purpose of the paper is to analyze and to detail the physical properties (SR EN ISO / CEI 322 for moisture content by method of drying and weighing, and effective density method according to SR EN ISO / CEI 323: 2005) and calorific properties of these briquettes (high and low calorific value according to ÖNORM M7135 using the XRY-1C / China Calorimeter and ash content according to ASTM D1102-84: 2013 and ISO 18122: 2015) and to make a comparison between these briquettes and other briquettes obtained from wooden biomass. The tested briquettes had a moisture content of $8 \%$, an effective density of $1214 \mathrm{~kg} / \mathrm{m} 3$, a high calorific value of $17.670 \mathrm{MJ} / \mathrm{kg}$, the low of $17.525 \mathrm{MJ} / \mathrm{kg}$ and an ash content of $5.6 \%$. All these values correspond to the permissible limits of the standards in the field. The final conclusion of the paper shows that wheat straw briquettes had physical and calorific properties similar to those of wooden biomass.
\end{abstract}

\section{Introduction}

The vegetal biomass participates within the carbon cycle in nature, by using the carbon dioxide and eliminating the oxygen in nature [1]. The carbon dioxide participates in the photosynthesis process during the growth of vegetal matter, but it is the component which determines a burn out during the photosynthesis, approximately $1 \%$ from the energy received from the sun is transformed into chemical energy by the plants during their growth. The solar energy absorbed by the biomass forms the chemical structure of the biomass components, respectively the celluloses, hemicelluloses and the lignin [2]. The biomass is environmentally friendly and a neutral energy in comparison to the carbon dioxide emissions [3]. The carbon dioxide is absorbed by the plants during the growth and forms a closed circuit, because the carbon dioxide which was absorbed by the plants during the growth will equal the same quantity which was eliminated during the burn out processes [4]. The biomass can be used in the combustion process and mostly this doesn't need huge investments in comparison to the hydro, solar, wind or geothermal energy [5].

*Corresponding author: cosmin.spirchez@unitbv.ro 
Presently, the biomass contributes with approximately $12 \%$ to the production of primary energy in the world, and in the countries in a development process it covers 40 $50 \%$ of the energy necessary supply. Biomass is an alternative energy source (in comparison to the energy resulted from fossil fuels), which contributed with $7 \%$ of the energy produced worldwide. At the present it is noticed that the use of biomass is continuously growing [6]. This growth is materialized by the manners of using the biomass and the products resulted by processing the biomass, separated in materials for biogas and bio-fuel production [7]. The productions of liquid fuels from lingo-cellulosic species have a potential to reduce the quantity of volatile substances released in the atmosphere by the oil products. On the Romanian territory there can be obtained fuels such as: bio-ethanol, vegetal oils, biodiesel, biogas, synthesis bio-fuels, bio-methanol and hydrogen [8-10]. The vegetal plants from which these fuels can be obtained are: sugar sorghum, sugar beetroot, straws, as well as other bio raw materials: organic waste used comestible oils, household wastes [11]. The European Union expects the introduction of the biogas in energy production, which will occupy in 2020 around $12 \%$ of the energy production, obtained from renewable energy sources [12]. The agricultural biomass is characterized by the diversity of the cereal and feed plants approximately 21-24 t / ha, for the biomass of the grains it is noticed a capacity of $12.5 \mathrm{t} / \mathrm{ha}$ [13].

A significant quantity of biomass is represented by the residues of agricultural crops represented by the parts of grown plants which remain on the field after harvest (corn cobs, leaves and corn husks, cereal straws, etc.) [14]. In the specialty literature it is estimated that the energetic potential of the biomass in 20150 will be $1500 \mathrm{EJ} /$ year $\left(1 \mathrm{EJ}=10^{18} \mathrm{~J}\right)$. The forest and agricultural biomass will offer annually a capacity of 50-150 EJ/year [15]. This scenario encourages enormously the research policies for obtaining new energetic resources, which shall contribute to the growth of energy production [16]. From the qualitative point of view, the annual plants are comparable to the wood, as follows: wheat straws have a celluloses content comprised between $30-40 \%$, lignin $16-21 \%$, the average length of fibers is $1.50 \mathrm{~mm}$, the hempseed has a celluloses content of $57-77 \%$, lignin 9$13 \%$, the average length of fibers is $25 \mathrm{~mm}$, the flax has the celluloses content comprised between $60-68 \%$, lignin content between $8-10 \%$, the average length of fibers is $33 \mathrm{~mm}$, the sun flower stems have a content of celluloses comprised between 33-42\%, lignin content between $5-8 \%$, the average length of fibers is $1.1 \mathrm{~mm}$, rapeseed has a celluloses content between $40-45 \%$, lignin content between $8-13 \%$, the average length of fibers is $1.8 \mathrm{~mm}$, spruce wood has a celluloses content between 50-57\%, lignin content between $27-33 \%$, the average length of fibers is $3.3 \mathrm{~mm}$, poplar wood has celluloses content between $45-50 \%$, lignin content between $16-24 \%$, the average length of fibers is $1 \mathrm{~mm}[16,17]$. It is noticed that the annual plants contain larger quantities of celluloses than the wood and less lignin. The average length of fibers from the annual plants is between the broadleaf fibers length (poplar) and coniferous (spruce) [18].

Briquettes and pellets are solid fuels of last generation made by high pressures comprising the vegetal biomass (as straws, stems and sun flower seed husks, rapeseed and corn stems, etc.). [19] These briquettes have caloric powers equivalent to the fire wood, but they are its superior products by a superior density and a superior caloric density. Even if the ash content is higher (4-8\%) than the wood (0.4-1.2\%), the briquettes and the pellets made of straws are still superior fuels, due to the insignificant price of the raw materials and the superior physical - caloric characteristics.

With the constant growth of the energy price, the interest for the energetic exploitation of the vegetal biomass, especially the straws, increased as well. From the specialty literature the burn heat values for different types of biomass are: wood, $18.5-19.5 \mathrm{MJ} / \mathrm{kg}$, myscanthus, $17.6 \mathrm{MJ} / \mathrm{kg}$, wheat straws, $17.2 \mathrm{MJ} / \mathrm{kg}$, corn stems, $16 \mathrm{MJ} / \mathrm{kg}$, rapeseed stems 
16.5 MJ/kg, energetic coal $25 \mathrm{MJ} / \mathrm{kg}$, natural gas $35 \mathrm{MJ} / \mathrm{m}^{3}$. Figure 1 shows comparatively the caloric powers of these fuel materials.

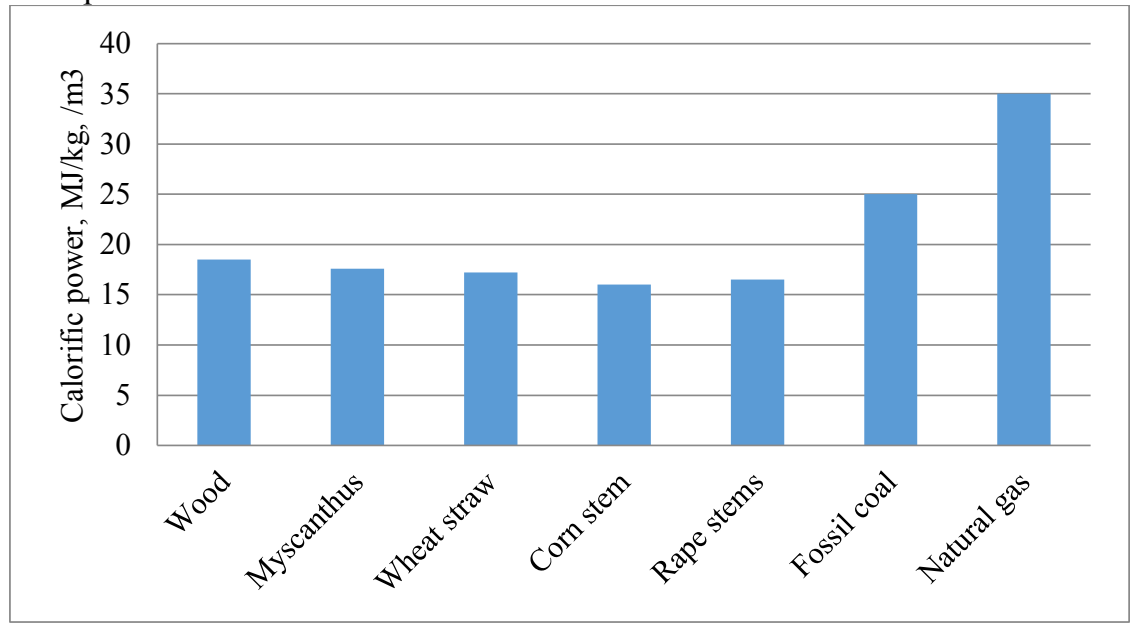

Fig. 1. The calorific power values of fuel materials

\section{Materials and Methods}

In order to determine the density of the straw briquettes and pallets, the classical method to determine their mass and volume and their report was used. Samples, over 20 pieces of each type, were taken from full briquettes and pellets and were cut in small pieces and the end were polished perpendicularly lengthwise, in order to obtain a clear length. The cylindrical shape was chosen for the briquettes because, only for this type the method to determine the perpendicular compression is applied, and the volume is easily determined, as volume of a smooth circular cylinder. The briquettes were weighted using an electronic scale TP KERN EW 1500-24 with a precision of 0.1 grams. It was as well determined the average diameter of the briquettes, as the average mean in three points (at the ends and middle), for two perpendicular diameters. The determination relation for density was the following:

$$
\rho=\frac{4 \cdot m}{\pi \cdot D_{m}^{2} \cdot l}\left[\mathrm{~g} / \mathrm{cm}^{3}\right]
$$

where: $\mathrm{m}$ - briquette or pellets weight, in $\mathrm{g}$;

$\mathrm{D}_{\mathrm{m}}$ - average diameter of the briquette, in $\mathrm{mm}$;

1- test tube length, in mm.

The moisture for the straw briquettes was accomplished by the classical method of weighting - drying - weighting of briquettes and was $8 \%$. The pellets testing is made according to own methodologies, standardized, respectively the density according to EN 15103. The limitative technical characteristics of the pellets according to the European standard EN 14961-2 is diameter: 4-10 mm, lengths: smaller than $50 \mathrm{~mm}$, density in bulk: $650 \mathrm{~kg} / \mathrm{m}^{3}$, effective density higher than $8 \%$, moisture lower than $8 \%$, ash content lower than $1.5 \%$, caloric power: $16.9-19.5 \mathrm{MJ} / \mathrm{kg}$, nitrogen content $<0.3 \%$ (for A1 class), $<0.5 \%$ (for A2 class), $<1,0$ (for B class), sulphur content $<0.03 \%$ (for A1 and A2 classes) and $<$ 0.04 (for B class), chloride content $<0.02 \%$ (for A1 and A2 content) and $<0.03 \%$

(for B class), determining ash content at temperatures $>1200{ }^{\circ} \mathrm{C}$ for $\mathrm{A} 1$ class and $>1100{ }^{\circ} \mathrm{C}$ for $\mathrm{A} 2$ and $\mathrm{B}$ class. 
For pellets the density in bulk was determined which was as average of $643 \mathrm{~kg} / \mathrm{m}^{3}$, with a variability of $\pm 20 \mathrm{~kg} / \mathrm{m}^{3}$.

The caloric power represents a heat quantity resulted while burning a unit of fuel mass. 8 findings were determined for the briquettes caloric power. The superior caloric power was determined (when water vapors condensate, releasing vaporizing heat) and the inferior caloric power (when a part of heating is lost for water evaporation). The inferior caloric power is obtained as difference between the superior caloric power and the heat quantity released for water evaporation from burning gases. The devices used for determining the caloric power for the four types of briquettes is the calorimetric bomb XRY-1C (made in China).

Before performing the proper essay, the calibration of the calorimetric bomb is made with benzoic acid (with a known caloric power of $26463 \mathrm{KJ} / \mathrm{kg}$ ), in order to determine the caloric coefficient of the calorimeter. The procedure to determine the caloric power of wood refers firstly to preparing the raw material (briquettes and pellets) and the installation, then the proper determination of the caloric power, and finally obtaining the results. The preparation of the wooden material for the testing consists in processing a small part of approximately $0.6-0.8$ grams of briquettes and pellets, samples weighted with a precision of 0.001 grams. This sample is put in a metallic pot and is introduced in a laboratory stove, in order to be dried at a temperature of $103 \pm 2{ }^{\circ} \mathrm{C}$. The final result of burning the lignocellulosic briquettes and pellets is expressed by the caloric power, notion through which one understands the heat quantity obtained by burning a mass unit. The proper test contains 3 distinct periods, respectively:

- The initial period ("before") which has as purpose the determination of the temperature variations of water in the calorimetric basin due to the heat exchange with the exterior before burning. In this period, usually 5 minutes, the temperature is read once at 1 minute with a precision thermocouple. The last temperature in the initial period is the first temperature in the main period. The registered values in this period are generally six and are registered once every 1 minute. After registering, the sixth value the ignition of the material takes place and indicating it in the menu bar under the name (Burning time).

- The main period ("main"), starts by igniting the sample and has as consequence the raise of water temperature in the calorimetric basin due to the burning of the briquette and pellets particle and heat releasing. The final temperature is given by the maximum value of the temperature, because after it's decreasing, that means that the calorimetric basin does not receive heat from the bomb. The values number may vary between 19-42 values of the registered temperature in this period.

- The final period ("after") has as purpose the determination of the average water temperature variation in the calorimetric basin, due to the heat exchange from the bomb with its exterior (water in the calorimetric basin) after burning.

In order to determine the ash content of briquettes and pellets, the general method of standardized determination (ASTM D2866-11, 2012) was used. According to this method, the ground and dried material to $0 \%$ humidity is calcined at a temperature of $650{ }^{\circ} \mathrm{C}$ in a lab stove, for at least 3 hours. The advanced burning operation is made on a high temperature proof metallic pot and the weighting was made on analytic scales with a precision of 3 decimals. When determining the ash content, it will be taken into consideration that the ash content is completely dried and the pot is clean and empty:

$$
A_{c}=\frac{m_{f}-m_{c}}{m_{i}-m_{c}} \cdot 100[\%]
$$

where:

$\mathrm{A}_{\mathrm{c}}$ - ash content, in \%

$\mathrm{m}_{\mathrm{i}}$ - initial mass of the pot with the work ground sample, in $\mathrm{g}$; 
$\mathrm{m}_{\mathrm{f}}$ - final mass of the pot with ash, in $\mathrm{g}$;

$\mathrm{m}_{\mathrm{c}}$ - empty pot weight, in $\mathrm{g}$.

\section{RESULTS AND DISCUSSION}

After determining on an experimental manner, it was found for straw briquettes the effective density of $1214 \mathrm{~kg} / \mathrm{m}^{3}$, and for straw pellets $1029 \mathrm{~kg} / \mathrm{m}^{3}$. Figure 2 presents comparatively the effective density values for the two types of biomass (wheat straw briquettes and pellets).

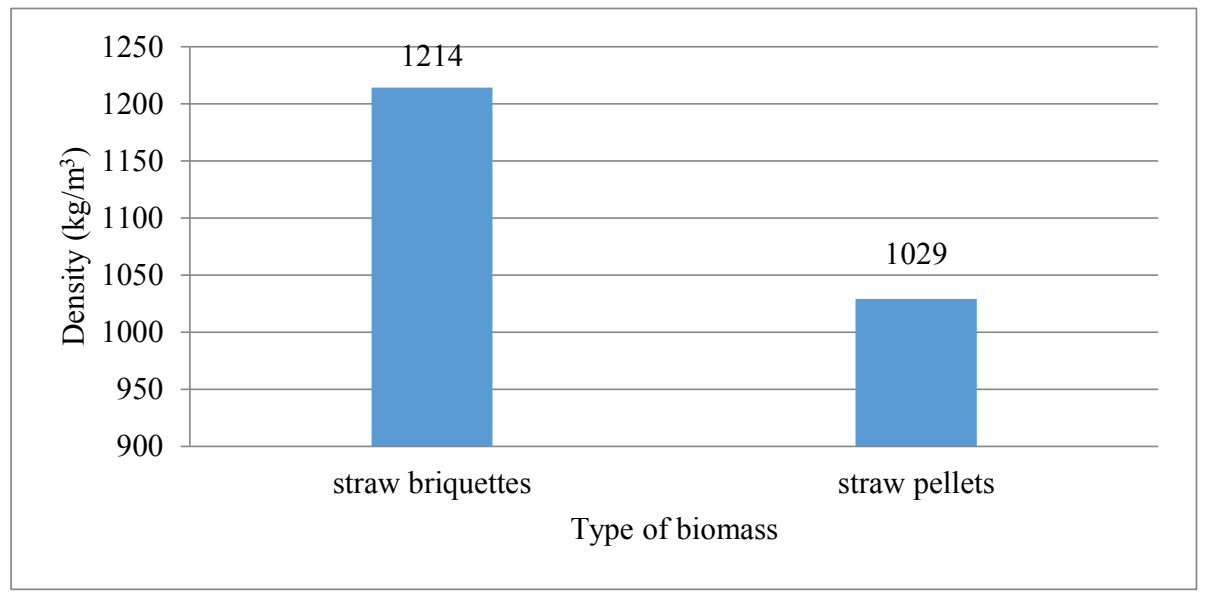

Fig. 2. Density for straw briquettes and pellets

From the above presented values, it is noticed that the agricultural wastes (wheat straws) has caloric powers near to the fire wood, and from this point of view they represent a valuable energetic source. After the experimental determination the superior caloric power for straw briquettes is higher than the pellets. Figure 3 presents the caloric power values for the two types of biomass.

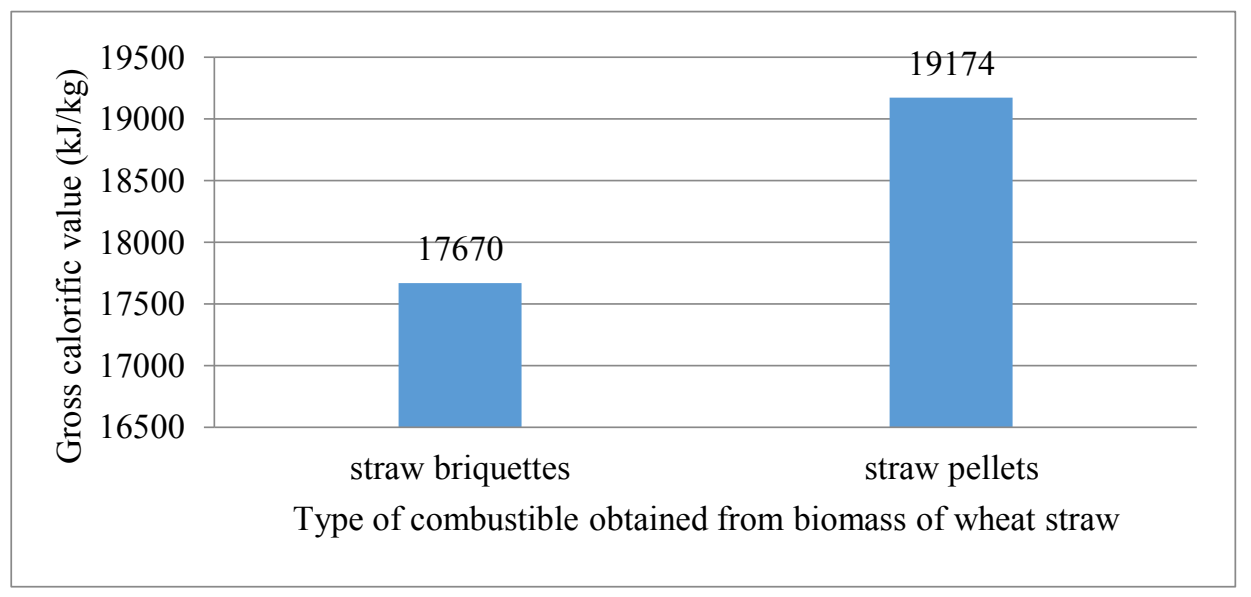

Fig. 3. Values of the gross calorific power for wheat straw briquettes and pellets 
Figure 4 presents comparatively the ash content values for the two types of fuels obtained from the wheat straws biomass.

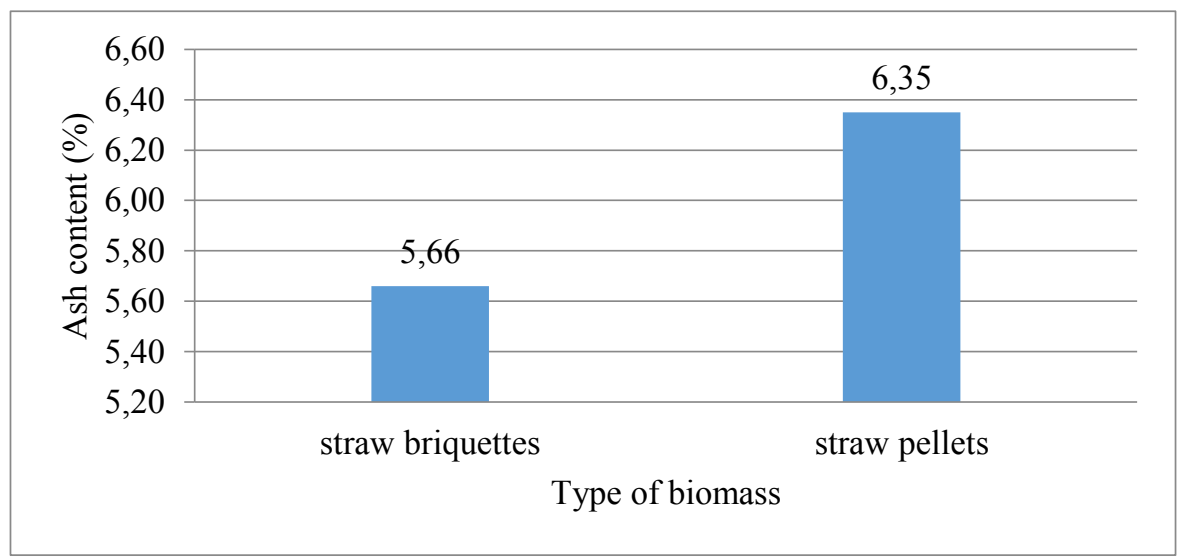

Fig. 4. The values of the ash content for straw briquettes and pellets

The ash content obtained from straw briquettes is classified according to the European standards (ASTM D1102-84:2013 and ISO 1822:2015) below the value of 6\%. The pellets have a higher ash content, because of the silicate dioxide and silicates content with a percent of $4.5 \%-5.5 \%$ from the total weight of the sample.

At the moment the economic market confronts with the decrease of the fossil fuels resources. The material obtained from the biomass produces a high quantity of energy, which may be available for any consumer. The unit cost of agricultural waste is inferior to the wood, and their usage as fuel requires the coverage of a track which includes baling, transportation, storage, loading, pelleting, and briquetting. As well, the agricultural wastes and especially the straws have higher ash content. A ton of straws completely dried develops theoretically the same quantity of heating which results through the burning of 0.67 energetic coals or $490 \mathrm{~m}^{3}$ gas. In the field of dwelling heating, there is a tendency to stop using the methane and butane gas and the heating with briquettes and pellets is preferred, including the wheat straws ones.

\section{Conclusions}

The vegetal biomass represents a new renewable energy source, because it is not left to degrade on the field and is used efficiently as solid fuels, respectively as briquettes and pellets. This does not contribute to the problem of changing the environment, because it recycles the carbon dioxide in the atmosphere. The experimental study in the paper highlights densities of 1214 and $1029 \mathrm{~kg} / \mathrm{m}^{3}$, for briquettes and respectively pellets. These high densities, with approximately $70 \%$ higher than the fire wood (in the beech species Fagus sylvatica L), make possible an increasing of the efficiency of combustion especially for central heating, by extending the combustion time of one batch.

The superior caloric power of pellets of $1917 \mathrm{~kJ} / \mathrm{kg}$ make possible the classification of this vegetal fuel in the category of high-performance solids. As a general conclusion, it may be stated that the transformation of the wheat straws in briquettes and pellets lead to obtaining some solid fuels with caloric proprieties superior to the wood fire (which is less and less on the fuels market). 


\section{References}

1. J.P. Boutin, G. Gervasoni, R. Hlep, K. Seyboth, P. Lamers, M. Ratton, K. McCormick, L. Mundaca, A. Plepys, Environ. Eng. Manag. J. 6, 1 (2007)

2. A. Demirbas, Energ. Convers. Manage., 42, 11 (2011)

3. J. Swithenbank, Q. Chen, X. Zhang, V. Sharifi, M. Pourkashamiani, Biomass Bioenerg. 37 (2011)

4. C. Ciubota-Rosie, M. Gavrilescu, M. Macoveanu, Environ. Eng. Manag. J., 7, 5 (2009)

5. J. Lako, J. Hancsok, T. Yuzhakova, G. Marton, A. Utsai, A. Redey, Environ. Eng. Manag. J., 7, 5 (2009)

6. V.K. Verna, S. Bram, J. de Rucky, Biomass Bioenerg, 33, 10 (2009)

7. O.O. Fasina, Physical properties of peanut hull pellets, Bioresource Technol. 99, 5 (2008)

8. A.V. Bridgwater, Biomass Bioenerg., 38 (2012)

9. D. Gavrilescu, Environ. Eng. Manag. J., 7, 5 (2008)

10. C. Gong, D. Lu, G. Wang, L. Tabil, D. Wang, BioResources 10, 3 (2015)

11. N. Kaliyan, R.V. Morey, Biomass Bioenerg., 33, 3 (2009)

12. M. Gavrilescu, Environ. Eng. Manag. J., 7, 5 (2008)

13. N.A. Pambudi, K. Itaoka, A. Chapman, N.D. Hoa, N. Yamakawa, International Journal of Smart Grid and Clean Energy, 6, 2 (2017)

14. A. Lunguleasa, Environ. Eng. Manag. J. 9,7 (2010)

15. C. Okello, S. Pindozzi, S. Faugno, L. Boccia, Biomass Bioenerg., 56 (2013)

16. N.M. Moisei, A.C. Puitel, D. Gavrilescu, B.M. Tofanica, Celuloza si Hartie, 63, 1 (2014)

17. B.M. Tofanica, D. Gavrilescu, Celuloza si Hartie 63, 1 (2014)

18. A. Lunguleasa, C. Spirchez, Wood Research 60, 5 (2015)

19. N.P.K. Nielsen, D.J. Gardner, T. Poulsen, C. Felby, Wood Fiber Sci 41, 4 (2009) 